\title{
THERMALLY AND MECHANICALLY INDUCED REGELATION OF ICE
}

\author{
by
}

\section{KAORU HORIGUCHI}

Institute of Low Temperature Science, Hokkaido University, Sapporo, Japan 060

\author{
R. D. MILLER
}

Department of Agronomy, Cornell University, Ithaca, NY 14853, USA

\begin{abstract}
At temperatures slightly below $0^{\circ} \mathrm{C}$, ice filling a smooth-walled chamber that has porous phase barriers at either end can move through the chamber in a process resembling regelation; supercooled water passes through one barrier and freezes at the same time that ice melts at the other, emerging through the second barrier as supercooled water. The process may be induced mechanically (by differential water pressures at the phase barriers) or thermally (by imposed temperature differentials). The ice moves as a rigid body with slippage at the ice-wall boundary of the chamber. An apparent coefficient of static friction can be deduced and appeared to be about 0.12 for ice at a machined nylon wall at about $-0.04^{\circ} \mathrm{C}$.
\end{abstract}

\section{INTRODUCTION}

In the well known demonstration of regelation, a weighted wire moves downward through a solid block of ice held at a temperature near its melting point (cf Tozuka and Wakahama 1983). Ice beneath the wire melts and the heat of fusion is absorbed from the surroundings; melt water passes around the wire and refreezes above it, returning the heat of fusion to the surroundings.

An "ice sandwich apparatus" (Figure 1) is a device that allows a different form of regelation to be induced

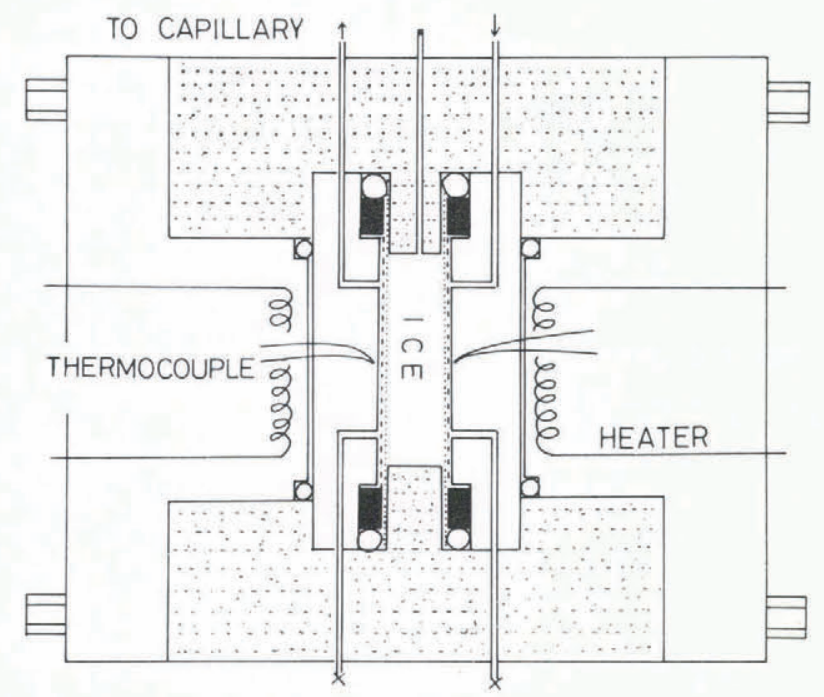

Fig.1. Ice sandwich apparatus, in cross-section. Freezing of the central chamber is nucleated by means of a side tube (top, center). From center chamber to either side, components are: Phase barrier (Millipore filter); Support screen, stainless steel mesh; Copper screen support with ports and thermocouples; Water gap (nominary $0.2 \mathrm{~mm}$ ); Copper end member with heated coil. Shaded area represents members machined from nylon. All parts and chambers would appear circular in plan view.
(Miller 1970, 1973). It consists of three rigid chambers in tandem with the middle chamber separated from its neighbors by porous phase barriers, walls that are pervious to liquid water but impervious to ice, at least over a range of conditions that are determined by the size of the largest water-filled channel. If the device is first filled with water, then cooled by immersion in a well-stirred bath at a temperature slightly below $0^{\circ} \mathrm{C}$, and if freezing of water is seeded in the central chamber, that chamber will soon be fully occupied by ice which remains "sandwiched" between the phase barriers if the substrate of the barrier is inherently hygroscopic and if the pores are small enough. The ice phase will be held at a distance from the substance of the barrier by adsorbed films of mobile water and will remain excluded from pores as a consequence of the specific surface free energy ("surface tension") of the ice-water interface. Thus, water in the end chambers is supercooled but can remain indefinitely in a state of metastable equilibrium with ice sandwiched between the phase barriers. Moreover, if conditions at the respective phase barriers are perturbed, the device can transmit $\mathrm{H}_{2} \mathrm{O}$ by a process that is diagrammed below

$$
\begin{array}{cc}
\text { Phase } & \text { Phase } \\
\text { Barrier 1 } & \text { Barrier 2 } \\
\left(\mathrm{u}_{\mathrm{w}}, \mathrm{u}_{\mathrm{i}}, \theta\right)_{1} & \left(\mathrm{u}_{\mathrm{w}}, \mathrm{u}_{\mathrm{i}}, \theta\right)_{2}
\end{array}
$$

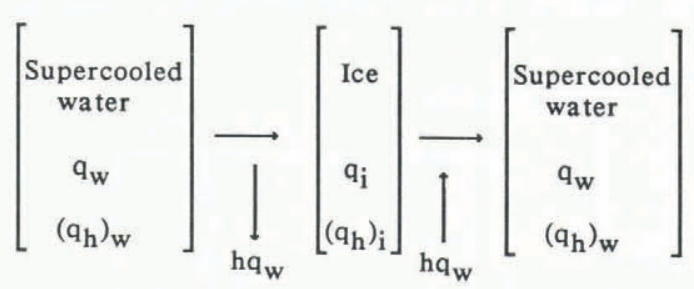

where $\mathrm{q}_{\mathrm{w}}$ and $\mathrm{q}_{\mathrm{i}}$ are volumetric fluxes of water and ice; $q_{h}$ is the flux of sensible heat; $h$ is the sensible heat released by freezing of unit volume of water; $u_{w}$ and $u_{i}$ are standard gauge pressures of water and ice (measured with respect to standard atmospheric pressure); $\theta$ is temperature in degrees Celsius.

Originally described as a functional semi-permeable membrane (Miller 1970, 1973), the ice sandwich has been adapted for use as a permeameter for frozen soil sandwiched between the phase barriers (Miller, Loch and Bresler 1975; Horiguchi and Miller 1980, 1983). The purpose of this paper is to illustrate how it might be used for studying friction between slow-moving ice and any substance that might be used in the walls of the central chamber between the phase barriers at temperatures very close to the melting point of ice. The conditions are unlike those which involve pressure-melting (Reynolds 1899), friction melting (Bowden and Hughes 1939) or adhesion theory (Tsushima 1977). 
THE GENERALIZED FORM OF THE CLAUSIUSCLAPEYRON EQUATION

The most familiar form of the Clausius-Clapeyron equation, given in elementary textbooks, is actually a special case of a more general relationship also given in some of those same books. In notation suitable for this paper, the more general form can be written (for pure $\mathrm{H}_{2} \mathrm{O}$ )

$$
\mathrm{u}_{\mathrm{w}}-\mathrm{u}_{\mathrm{i}} / \mathrm{G}_{\mathrm{i}}=(\mathrm{h} / 273) \theta
$$

where $u_{w}, u_{i}, h$ and $\theta$ have already been defined; $G_{i}$ is the ratio of the density of ice to that of water.

Comparing conditions at ice-water interfaces at the two phase barriers, we define $\Delta \mathrm{u}_{\mathrm{w}}=\left(\mathrm{u}_{\mathrm{w}}\right)_{2}-\left(\mathrm{u}_{\mathrm{w}}\right)_{1} ; \Delta \mathrm{u}_{\mathrm{i}}=$ $\left(\mathrm{u}_{\mathrm{i}}\right)_{2}-\left(\mathrm{u}_{\mathrm{i}}\right)_{1} ; \Delta \theta_{\mathrm{i}}=\theta_{2}-\theta_{1} ; \overline{\mathrm{u}}_{\mathrm{w}}=\left[\left(\mathrm{u}_{\mathrm{w}}\right)_{1}+\left(\mathrm{u}_{\mathrm{w}}\right)_{2}\right] / 2 ; \bar{u}_{\mathrm{i}}=$ $\left[\left(u_{i}\right)_{1}+\left(u_{i}\right)_{2}\right] / 2 ; \bar{\theta}=\left(\theta_{1}+\theta_{2}\right) / 2$. Thus, from Equation 1 we find

$$
\begin{aligned}
& \Delta \mathrm{u}_{\mathrm{w}}-\Delta \mathrm{u}_{\mathrm{i}} / \mathrm{G}_{\mathrm{i}}=(\mathrm{h} / 273) \Delta \theta_{\mathrm{i}} \\
& \overline{\mathrm{u}}_{\mathrm{w}}-\overline{\mathrm{u}}_{\mathrm{i}} / \mathrm{G}_{\mathrm{i}}=(\mathrm{h} / 273) \bar{\theta}
\end{aligned}
$$

\section{WALL FRICTION}

If ice is to slide in a cylindrical chamber of radius $R$ and length $\mathrm{L}$ containing ice at an average pressure $\bar{u}_{i}$ and driven by a pressure differential $\Delta \mathrm{u}_{\mathrm{i}}$, a coefficient of friction $\mu$ can be defined by

$$
\mu=-\left(\pi R^{2}\right) \Delta u_{i} /\left(2{ }_{n} R L\right) \bar{u}_{i}=(R / 2 L)\left(\Delta u_{i} / \bar{u}_{i}\right)
$$

In this paper, we will evaluate $\mu$ from data obtained with ice in motion, extrapolated to zero rate of movement where movement is evaluated from measurement of the flux of water $q_{w}$ in one of the end chambers,

$$
\mu=-\operatorname{Lim}(\mathrm{R} / 2 \mathrm{~L})\left(\Delta \mathrm{u}_{\mathrm{i}} / \overline{\mathrm{u}}_{\mathrm{i}}\right)
$$

Only this special case will be considered because to evaluate $\Delta \mathrm{u}_{\mathrm{i}}$ it is necessary to know both $\Delta \mathrm{u}_{\mathrm{w}}$ and $\Delta \theta_{\mathrm{i}}$ in Equation 2. While $\Delta u_{w}$ can be controlled, $\Delta \theta_{i}$ cannot be conveniently controlled nor conveniently measured and it will depend upon $q_{w}$, as will be shown.

\section{APPARATUS AND PROCEDURE}

The ice sandwich apparatus (Figure 1) and the associated control and measuring system (Figure 2) have been described in some detail elsewhere (Horiguchi and Miller 1980). Millipore filters (GSWP 04700) were used as

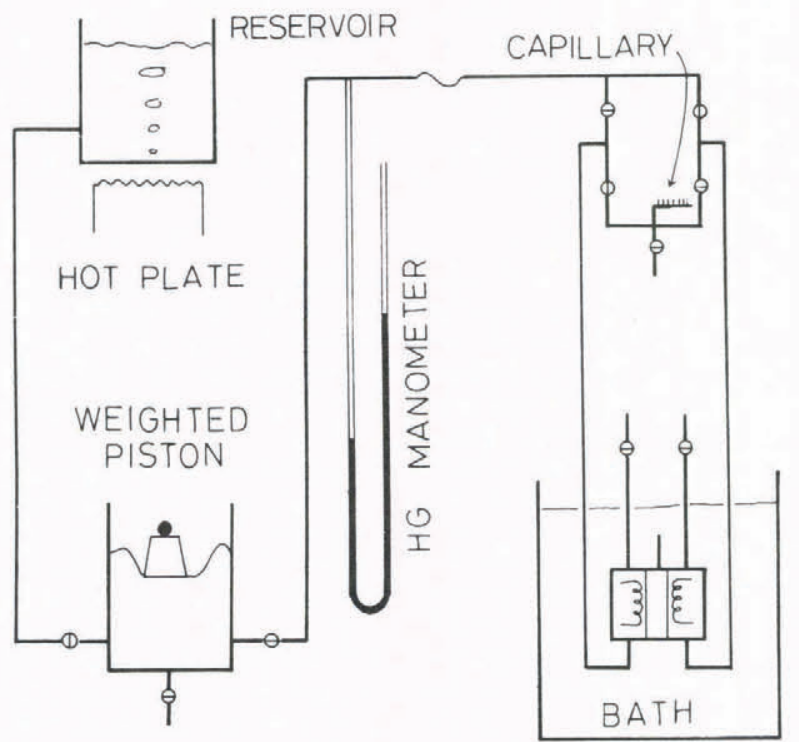

Fig.2. Schematic diagram of measurement and control system. Note valves for flushing and flow reversal. phase barriers and were supported by stainless steel mesh (Millipore $\$ 2004708$ ) which rested on copper supports into which thermocouple junctions had been cemented. Except for a thin rim at the outer edge, the copper supports were each separated from a second copper assembly by a $0.2 \mathrm{~mm}$ water-filled gap. Inside each copper assembly was a winding of nichrome wire sometimes used as an electric heating element with DC current provided by a regulated power supply. Care was taken to achieve a high degree of symmetry between the respective sides of the ice sandwich apparatus.

Reference junctions for both thermocouples were within insulating tubing immersed in the constant temperature bath. Outputs from individual thermocouples, or differential outputs of both thermocouples were observed with a digitial nanovoltmeter with all-copper leads and connectors.

Bath temperature was adjustable and its temperature was monitored with a rapid-response resistance thermometer connected to a Wheatstone bridge whose amplified output was recorded on a strip chart which showed that temperature fluctuations of the control cycle seldom exceeded $0.001{ }^{\circ} \mathrm{C}$ and that drift was usually imperceptible over periods of many hours. The sensitivity of the resistance thermometer was calibrated against a certified Beckman thermometer but the accuracy of the ice-bath calibration of the Beckman thermometer may have been no better than $\pm 0.003^{\circ} \mathrm{C}$

When appropriate, the entire system, or parts of it, were flushed with deaired deionized distilled water drawn from an actively boiling reservoir. Water in the chamber connected to the calibrated capillary used for measuring $\mathrm{q}_{\mathrm{w}}$ was at a fixed pressure $4.0 \mathrm{kPa}$ determined by the elevation of the horizontal capillary (open to the atmosphere) above the chamber. Water in the other chamber could be held at that same pressure or at a higher pressure controlled by a weighted piston.

The flux of water $q_{w}$ was recorded as positive when water was entering the capillary or negative when water was being withdrawn from it. The mean temperature of the

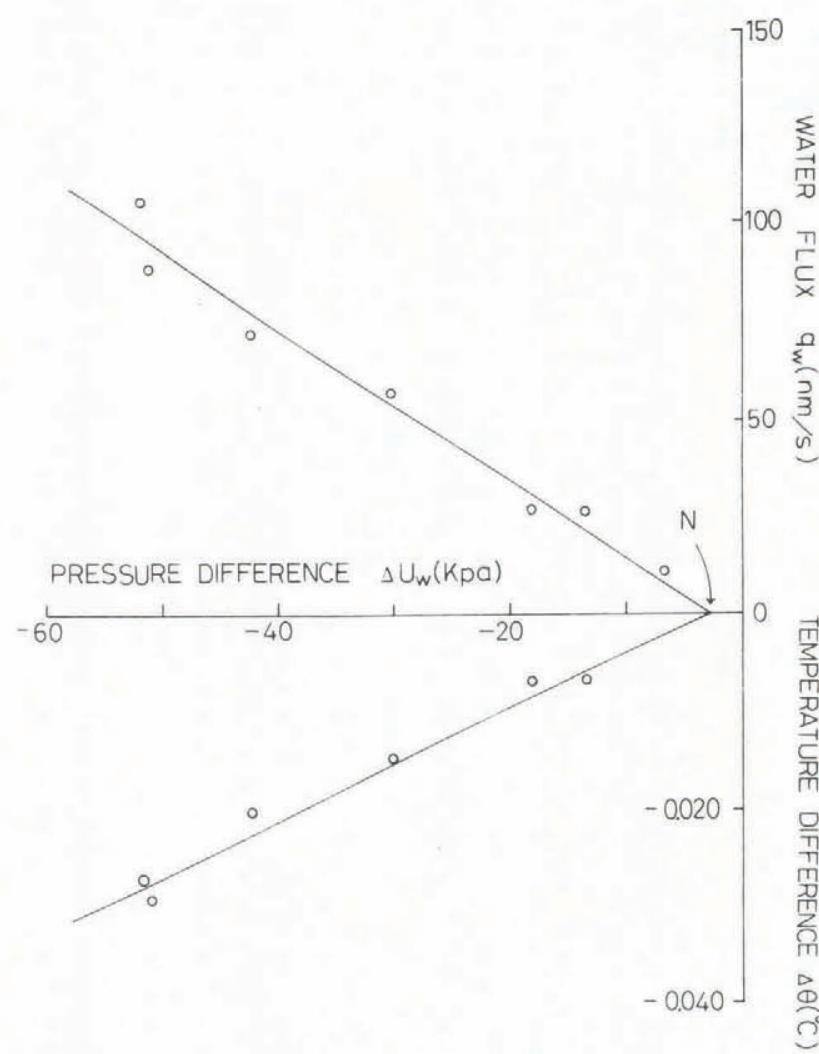

Fig.3. Water flux $\mathrm{q}_{\mathrm{w}} \mathrm{cm}^{3} \mathrm{H}_{2} \mathrm{O}$ per $\mathrm{cm}^{2}$ of phase barrier and temperature difference $\Delta \theta$ at thermocouples induced by differential water pressure $\Delta \mathrm{u}_{\mathrm{w}}$ in end transport was toward low-pressure chamber. Heaters were both off. 
middle chamber was taken to be equal to the bath temperature when no heater was operative $\left(-0.041 \pm 0.002^{\circ} \mathrm{C}\right)$ but equal to the average values measured with the two thermocouples when a heater was operating. each time that heater current was changed, bath temperature was adjusted to restore the average temperature of the ice chamber to the same value, $-0.040 \pm 0.003$.

The middle chamber had a radius $\mathrm{R}=1.60 \mathrm{~cm}$ and a length $\mathrm{L}=0.30 \mathrm{~cm}$. The filter and wire mesh screen had a combined thickness of about $0.25 \mathrm{~mm}$.

\section{RESULTS}

With neither heater in action, the dependence of $q_{w}$ and $\Delta \theta$ on the pressure difference $\Delta \mathrm{u}_{\mathrm{w}}$ is shown in Figure 3; Figure 4 shows the relationship between $\mathrm{q}_{\mathrm{w}}$ and $\Delta \theta$ when $\Delta u_{w}$ was zero. In neither case was $\Delta \theta_{i}$ (Equation 3) known since $\Delta \theta$ represents values observed using

TEMPERATURE DIFFERENCE $\Delta \theta\left({ }^{\circ} \mathrm{C}\right)$

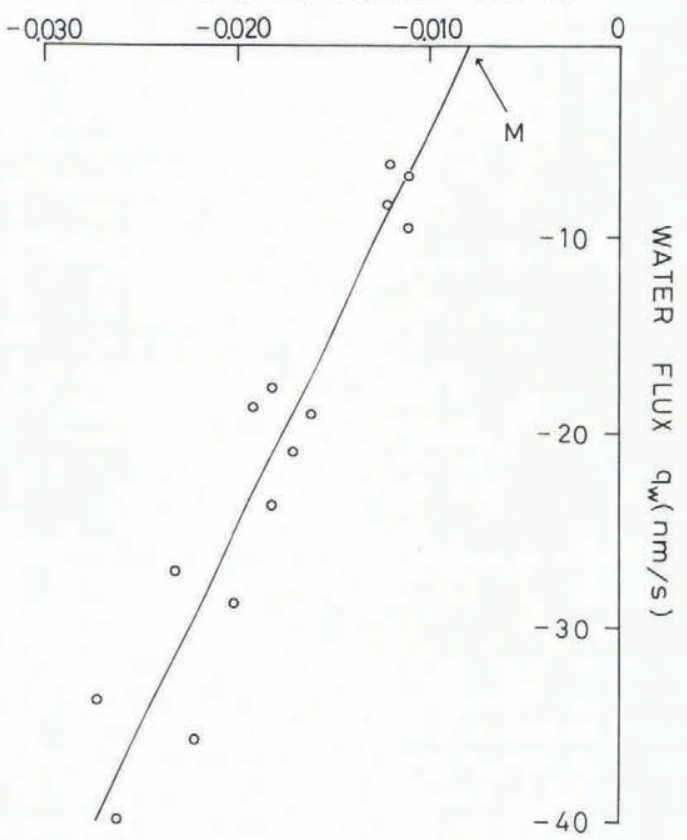

Fig.4. Water flux $\mathrm{q}_{\mathrm{w}}$ and temperature difference at thermocouples $\Delta \theta$ when one heater was on but water pressures in end chambers were equal. Average ice temperature: $-0.040^{\circ} \mathrm{C}$. Transport was toward the warm side.

themocouples at finite distances from the ice-water interfaces at the phase barriers.

Figure 3 demonstrates mechanically-induced regelation and associated thermal effects; transport was from the higher water pressure to the lower one; heat was being released at the interface on the high pressure side and absorbed on the low pressure side; $\Delta \theta_{i}$ was greater than $\Delta \theta$ observed.

Figure 4 demonstrates thermally-induced regelation; transport was from the colder side to the warmer side; $\Delta \theta_{i}$ was less than $\Delta \theta$ observed. In both cases, no transport was observed until a threshold value of $\Delta \mathrm{u}_{\mathrm{w}}$ or $\Delta \theta$ had been exceeded.

Using the intercept (point $\mathrm{N}$ ) to estimate $\mu$ in Equation 3, $\left(\Delta \theta_{\mathrm{i}}\right)_{\mathrm{N}}=0 ;\left(\Delta \mathrm{u}_{\mathrm{w}}\right)_{\mathrm{N}}=-2.5 \mathrm{kPa} ;\left(\Delta \mathrm{u}_{\mathrm{i}}\right)_{\mathrm{N}}=-0.917$ $\left(\Delta \mathrm{u}_{\mathrm{w}}\right)_{\mathrm{N}}=-2.3 \mathrm{kPa} ; \bar{\theta}=-0.041_{ \pm} \pm .002^{\circ} \mathrm{C} ; \overline{\mathrm{u}}_{\mathrm{w}}=[4.0+(4.0$ $+2.5)] / 2=5.25 \mathrm{kPa} ; \overline{\mathrm{u}}_{\mathrm{i}}=0.917\left[\overline{\mathrm{u}}_{\mathrm{w}}-(\mathrm{h} / 273) \bar{\Theta}\right]=50.8 \pm 3.7$ $\mathrm{kPa} ; \mu=0.12$ for ice and machined nylon at $-0.04^{\circ} \mathrm{C}$.

\section{CONCLUSIONS}

Performance of the ice sandwich apparatus is indeed consistent with both mechnaically and thermally-induced regelation processes and it could be used for evaluations of friction between ice and other substances at very low velocities at temperatures very near the melting point of ice.
Thermally-induced regelation in a process water $\rightarrow$ ice $\rightarrow$ water is in the direction of rising temperature and this is the reverse of the direction for the process ice $\rightarrow$ water $\rightarrow$ ice as observed for thermally-induced migration of isolated grains through ice (Romkens and Miller 1973).

\section{ACKNOWLEDGEMENT}

This work was suppported in part by NSF Grant No CME-8017422.

\section{REFERENCES}

Bowden F P, Hughes T P 1939 The mechanisms of sliding on ice and snow. Proceedings of the Royal Society of London A: 172(949): 280-298

Horiguchi K, Miller R D 1980 Experimental studies with frozen soil in an "ice sandwich" permeameter. Cold Regions Science and Technology 3: 177-183

Horiguchi K, Miller R D 1983 Hydraulic conductivity functions of frozen materials. Permafrost: Fourth International Conference Proceedings. Washington DC, National Academy Press: 504-508

Miller R D 1970 Ice sandwich: Functional semipermeable membrane. Science 169: 584-585

Miller R D 1973 The porous phase barrier and crystallization. Separation Science 8: 521-535

Miller R D, Loch J P G, Bresler E 1975 Transport of water and heat in a frozen permeameter. Soil Science Society of America Proceedings 39: 1029-1036

Reynolds O 1899 On the slipperiness of ice. Memoires and Proceedings of the Manchester Literary and Philosophical Society 43(2) No 5

Romkens M J M, Miller R D 1973 Migration of mineral particles in ice with a temperature gradient. Journal of Colloidal Interface Science 42: 103-111

Tozuka S, Wakahama G 1983 Studies in Regelation. Journal of Physical Chemistry 87: 4147-4154

Tsushima K 1977 Friction of a steel ball on a single crystal of ice. Journal of Glaciology 19: 225-235 